\title{
A STATISTICAL APPROACH FOR OBTAINING THE CONTROLLED WOVEN FABRIC WIDTH
}

\section{Khubab Shaker, Muhammad Umair, Muhammad Maqsood, Yasir Nawab, Sheraz Ahmad*, Abher Rasheed, Munir Ashraf, Abdul Basit}

\author{
Faculty of Engineering \& Technology, National Textile University, Faisalabad-37610, Pakistan \\ Office address: Department of Materials \& Testing, Faculty of Engineering \& Technology, National Textile University, \\ Sheikhupura Road, Faisalabad-37610, Pakistan \\ Email address: itsadeelnaz@hotmail.com
}

\begin{abstract}
:
A common problem faced in fabric manufacturing is the production of inconsistent fabric width on shuttleless looms in spite of the same fabric specifications. Weft-wise crimp controls the fabric width and it depends on a number of factors, including warp tension, temple type, fabric take-up pressing tension and loom working width. The aim of this study is to investigate the effect of these parameters on the fabric width produced. Taguchi's orthogonal design was used to optimise the weaving parameters for obtaining controlled fabric width. On the basis of signal to noise ratios, it could be concluded that controlled fabric width could be produced using medium temple type and intense take-up pressing tension at relatively lower warp tension and smaller loom working width. The analysis of variance revealed that temple needle size was the most significant factor affecting the fabric width, followed by loom working width and warp tension, whereas take-up pressing tension was least significant of all the factors investigated in the study.
\end{abstract}

\section{Keywords:}

Weaving parameters, Fabric width, Optimisation, Taguchi approach

\section{INTRODUCTION}

Weaving is the interlacement of two sets of yarns at right angles to each other[1]. One set of yarns runs in longitudinal direction (warp) and the other in crosswise direction (weft). Crimp is inserted during interlacement of the yarn sets. The extent of warp and weft crimp determines the fabric length and width vis-à-vis the length of yarns incorporated in that direction. Higher the stress on warp yarns during weaving, lower will be the crimp inserted in the warp and higher will be the crimp in the weft[2]. When woven on loom, fabric width is equal to the reed within the vicinity of the reed. However, as the fabric gets away from the reed or is taken off the loom, it narrows down in width. So, the on-loom width corresponds to the reeded width, while off-loom width is the width after weft contraction when it is taken off the loom.

Fabric width is the most important parameter of fabric, affecting its properties. Inequality in the fabric width results in variation of porosity and air permeability. Also, the mechanical and physical properties of fabric are dependent on its width. If the fabric width achieved is not the same as required, there will be variation in the ends/inch and ultimately the GSM (grams per square meter) of fabric. The problem becomes even more severe if there is variation in the width of different looms running with the same construction. A variation in the fabric strength will be observed due to varying width and number of ends/inch of the fabric. Keeping in view the problem, the fabric can be rejected by the customer, if he is more concerned with the width, as in pattern making and cutting, it is essential to have a controlled fabric width.
Weft crimp is generally of more importance compared to warp crimp since variations in weft crimp will result in variation in the off-loom fabric width. The higher the weft contraction, lower will be the off-loom width. Weft crimp may be affected by different factors, like the tension on the weft yarn during insertion[3]. The tension is mostly set according to the type of weave design and the fabric construction, which further affects the fabric areal density[4].

Some fibre and yarn variables like fibre fineness, staple length, and twist in the weft also have significant influence on the amount of weft-way fabric contraction. Previous research has indicated a direct relationship of weaving contraction with fibre staple length and yarn twist while inverse relationship with fibre micronaire[5]. Core-spun cotton yarns, with elastane in the core, have become quite popular in the textile industry. Fabric containing such yarns have more contraction in width due to higher retraction force[6].

The yarn crimp is also considerably affected by thread count and filling density - coarser the weft yarn, more is the warp crimp[7]. But with increase in filling density and coarser thread count, the weaving becomes difficult due to increase in cover factor. Many other factors like warp tension at beat up, weaving resistance, and warp and weft densities in loom state are affected by changes in closed shed warp tension and running weft tension[8]. According to Adomaitene et al.[9] the initial warp tension and heald crossing moment changes the fabric structure parameters, thus changing the behaviour of the fabric. 
Loom working width is usually expressed in terms of reed space or useful reeding width. Looms with a variety of working widths are available in the market, ranging from 1500 to $3900 \mathrm{~mm}$. The crimp in the weft causes the fabric to contract, and outer ends causing a sideways pressure on the reed dents. It can cause the reed to get damaged. The temples are installed on the loom to grip the cloth at the fell, keeping it stretched to the same width as that of the reed [10]. They also help to keep the weft contraction in the beat up zone to the lowest. Most common types of temples include the ring temples, roller temples and full-width temples.

Ring temples are the most widely used type of temples. These temples have pinned rings, which penetrate in the cloth [11]. The pins do not exert force on weft, but directly on the warp. The length of pins is governed by the type of cloth being woven and is about 1.5-2 times the fabric thickness. Brass rings can be used for all types of fabrics, while for delicate fabrics, plastic rings are preferred.

Taguchi method is one of the most commonly used statistical methods for process optimisation with minimum number of experimental runs. It focuses on improving the fundamental function of a product or process, aiding in flexible designs, reducing product costs, improving quality and simultaneously reducing development time. The purpose of parameter design is to investigate the overall noise variation when the levels of the control factors are allowed to vary widely [12].

No significant work has been reported in the literature on the effect of temple type, loom working width, take-up pressing tension and warp tension on the off-loom fabric width obtained in weaving. The aim of this study is to optimise the temple type, loom working width, take-up pressing tension and warp tension for obtaining controlled off-loom fabric width for specific fabric construction, using Taguchi approach.

\section{Experimental}

The material used in this study was $100 \%$ cotton yarns and the weaving of samples was performed on Tsudakoma Air jet loom (Zax Professional 9100) equipped with tappet shedding system. The properties of warp and weft yarns used for this study are shown in Table 1. Both the warp and weft were $100 \%$ cotton, having comparable values of tenacity and elongation. The twist in yarn and imperfections are also given in Table 1.

The densities of warp and weft were 50.5 and 23.5 threads $/ \mathrm{cm}$, respectively, in the samples produced, while all the samples were woven in3/1 S Twill design.

The weaving parameters that were kept constant for all the fabrics are given in Table 2.

The variables and levels for each experimental variable are given in Table 3.

Taguchi Design of Experiment (TDOE) in Minitab ( $v$ 16.0) was employed for obtaining the orthogonal matrix given in Table 4.
Table 1: Properties of yarns used in present study

\begin{tabular}{|c|c|c|}
\hline Property & Warp yarn & Weft yarn \\
\hline Material & $100 \%$ cotton & $100 \%$ cotton \\
\hline Count (tex) & 30 & 630 \\
\hline $\begin{array}{c}\text { Twist per meter } \\
\text { (TPM) }\end{array}$ & 720 & $\mathrm{Z}$ \\
\hline $\begin{array}{c}\text { Twist direction } \\
\text { Uniformity (U) \% }\end{array}$ & 12.70 & 11.03 \\
\hline $\begin{array}{c}\text { Thick places, } \\
+50 \% / k m\end{array}$ & 234 & 87 \\
\hline Thin places, \\
-50\%/km
\end{tabular}

Table 2: Loom parameters observed during weaving fabric samples

\begin{tabular}{|c|c|c|}
\hline Parameters & Crank angle & Value \\
\hline RPM & - & 950 \\
\hline Beat up & $360^{\circ}$ & - \\
\hline Picking & $76^{\circ}$ & - \\
\hline Shed crossing & $290^{\circ}$ & 4 times \\
\hline Let-off & Continuous & - \\
\hline Take-up & Continuous & 76 mm \\
\hline $\begin{array}{c}\text { Maximum shed } \\
\text { opening }\end{array}$ & $180^{\circ}$ & $\begin{array}{c}\text { Horizontal }=5 \\
\text { mm }\end{array}$ \\
\hline $\begin{array}{c}\text { Back rest position } \\
\text { Easing: } 290^{\circ}\end{array}$ & Vertical $=45 \mathrm{~mm}$ \\
\hline
\end{tabular}

RPM: Revolutions per min

Table 3: Control factors and levels for experimental design

\begin{tabular}{|c|c|c|}
\hline Factors & Level 1 & Level 2 \\
\hline A: warp tension (N) & $4200 \mathrm{~N}$ & $5000 \mathrm{~N}$ \\
\hline B: temple needle & Fine & Medium \\
\hline $\begin{array}{c}\text { C: take-up pressing } \\
\text { tension }\end{array}$ & Medium & Intense \\
\hline $\begin{array}{c}\text { D: loom working } \\
\text { width (mm) }\end{array}$ & 1900 & 2100 \\
\hline
\end{tabular}


Table 4: L8 OA for samples production

\begin{tabular}{|c|c|c|c|}
\hline A & B & C & D \\
\hline 1 & 1 & 1 & 1 \\
\hline 1 & 1 & 2 & 2 \\
\hline 1 & 2 & 1 & 2 \\
\hline 1 & 2 & 2 & 1 \\
\hline 2 & 1 & 1 & 2 \\
\hline 2 & 1 & 2 & 1 \\
\hline 2 & 2 & 1 & 1 \\
\hline 2 & 2 & 2 & 2 \\
\hline
\end{tabular}

A: warp tension; B: temple needle; C: take-up pressing tension; D: loom working width $(\mathrm{mm})$

OA: Orthogonal array

After the production of fabric samples according to the TDOE, the off-loom width of the samples was tested according to ASTM (American Society of Testing \& Materials) D-3774 test method, using option $\mathrm{B}$ [13]. The steel tape used for measurement had $1 \mathrm{~mm}$ graduations and length greater than the width of fabric to be measured. The relaxation time for the measurement of fabric width was 24 hours.

\section{Results and Discussion}

The average values of off-loom fabric width after each experiment are listed in Table 5, including signal to noise $(\mathrm{S} / \mathrm{N})$ values calculated according to Equation (1) (for higher the better), where $n$ is the number of experiments in the orthogonal array and $y$ is the ith measured value of fabric width.

$$
S / N=-10 \log \left[\frac{1}{n} \sum_{i=1}^{n} \frac{1}{y_{i}^{2}}\right]
$$

$\mathrm{S} / \mathrm{N}$ value is the measure of performance variability of products/ processes in the presence of noise factors. It is a performance criterion, defined as the $\mathrm{S} / \mathrm{N}$ ratio, in that, $\mathrm{S}$ stands for mean and is called signal and $\mathrm{N}$ stands for standard deviation and is called noise [14]. The higher the $\mathrm{S} / \mathrm{N}$ value, better the quality of product.

For both levels 1 and 2, average $\mathrm{S} / \mathrm{N}$ ratio is given in Table 6 .

Table 6: Average S/N ratio at level 1 and level 2

\begin{tabular}{|c|c|c|c|}
\hline Factor & $\begin{array}{c}\text { Average } \\
\text { S/N ratio } \\
\text { (at level 1) }\end{array}$ & $\begin{array}{c}\text { Average } \\
\text { S/N ratio } \\
\text { (at level 2) }\end{array}$ & Delta \\
\hline A & $64.12^{*}$ & 64.10 & 0.02 \\
\hline B & 64.09 & $64.12^{*}$ & 0.03 \\
\hline C & 64.10 & $64.11^{*}$ & 0.01 \\
\hline D & $64.12^{*}$ & 64.10 & 0.02 \\
\hline \multicolumn{4}{|c|}{ *optimum factor level $^{2}$} \\
\hline
\end{tabular}

while the main effects plot for $\mathrm{S} / \mathrm{N}$ ratio are shown in Figure 1.

The delta values were calculated by subtracting the higher $S / N$ value from the lower value. The analysis of variance (ANOVA) for $\mathrm{S} / \mathrm{N}$ ratios is shown in Table 7 . P-values $<0.05$ indicate that the effect of terms $B$ and $D$ is statistically significant with more than $95 \%$ confidence, while the $p$-values $<0.1$ indicate that the terms $A$ and $C$ has significant effect on fabric width with $90 \%$ confidence. The R-sq value of the established linear model

Table 5: Experimental results of the samples produced

\begin{tabular}{|c|c|c|c|c|c|c|}
\hline \multirow[b]{2}{*}{ A } & \multirow[b]{2}{*}{ B } & \multirow[b]{2}{*}{ C } & \multirow[b]{2}{*}{ D } & \multicolumn{2}{|c|}{ Fabric width (mm) } & \multirow[b]{2}{*}{$\mathrm{S} / \mathrm{N}$ ratio } \\
\hline & & & & Average & $\begin{array}{l}\text { Standard } \\
\text { deviation }\end{array}$ & \\
\hline 4200 & Fine & Medium & 1900 & 1602.8 & 1.3038 & 64.0976 \\
\hline 4200 & Fine & Intense & 2100 & 1602.8 & 0.8367 & 64.0976 \\
\hline 4200 & Medium & Medium & 2100 & 1605.4 & 0.8367 & 64.1117 \\
\hline 4200 & Medium & Intense & 1900 & 1613.4 & 0.8367 & 64.1548 \\
\hline 5000 & Fine & Medium & 2100 & 1598.6 & 0.8367 & 64.0748 \\
\hline 5000 & Fine & Intense & 1900 & 1603.0 & 0.5477 & 64.0987 \\
\hline 5000 & Medium & Medium & 1900 & 1607.0 & 1.1402 & 64.1203 \\
\hline 5000 & Medium & Intense & 2100 & 1604.8 & 1.1402 & 64.1084 \\
\hline
\end{tabular}

A: warp tension; B: temple needle; C: take-up pressing tension; D: loom working width (mm) 


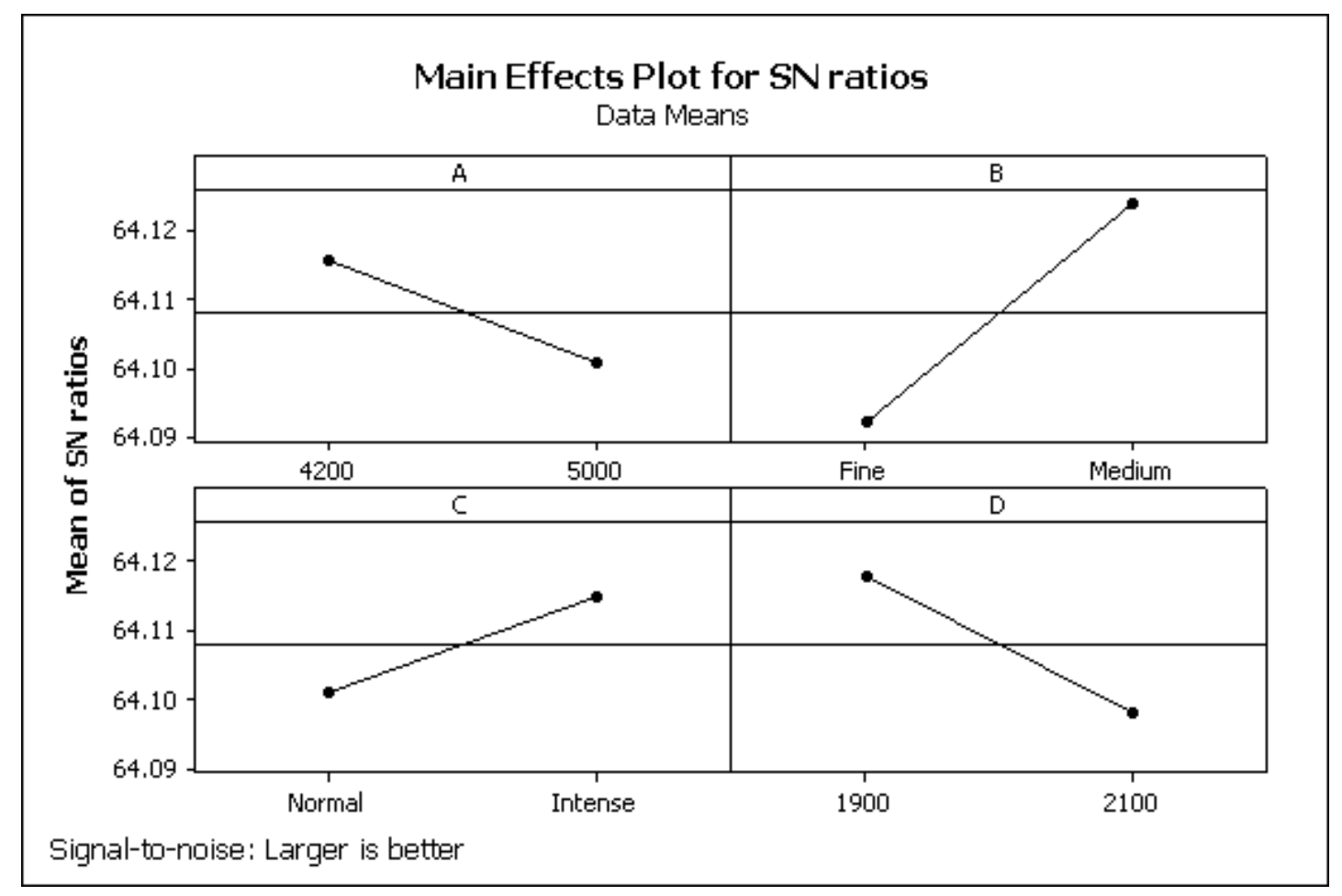

Figure 1: Main effects plot (data means) for $\mathrm{S} / \mathrm{N}$ ratios

Table 7: ANOVA for $\mathrm{S} / \mathrm{N}$ ratios

\begin{tabular}{|c|c|c|c|c|c|}
\hline $\begin{array}{c}\text { Source of } \\
\text { variation }\end{array}$ & $\begin{array}{c}\text { Degree of } \\
\text { freedom }\end{array}$ & Sum of squares & Mean square & F-ratio & p-value \\
\hline A & 1 & 0.000442 & 0.000442 & 8.25 & 0.064 \\
\hline B & 1 & 0.002004 & 0.002004 & 37.38 & 0.009 \\
\hline C & 1 & 0.000380 & 0.000380 & 14.54 & 0.076 \\
\hline D & 1 & 0.000779 & 0.000779 & & \\
\hline Residual error & 3 & 0.000161 & 0.000054 & & \\
\hline Total & 7 & 0.003766 & & & \\
\hline
\end{tabular}

ANOVA: Analysis of variance

was found to be $95.7 \%$, indicating that $95.7 \%$ variation in fabric width could be explained by the terms included in the model.

It is obvious from Figure 1 and the delta values from Table 6 that the fabric width is affected the most with factor $B$ (temple needle), followed by the factors $D$ (loom working width), $A$ (warp tension) and $\mathrm{C}$ (take-up pressing tension), respectively.

The fabric width increases with decrease in A (warp tension). At lower warp tension, the crimp in the warp will be higher but in the weft will be lower, a phenomenon known as crimp interchange[15].

The temple type has the most significant effect on the width of fabric. With fine needle type, the grip is not adequate enough to keep the fabric stretched compared to the medium needle type. Hence, medium temple needle results in higher fabric width compared to the finer temple needle.
With normal take-up pressing, the fabric contracts in the nip, causing a decrease in the fabric width. But in case of intense take-up pressing, more width is achieved.

In case of a wider width loom, the air pressure for weft insertion has the tendency to decrease at the receiving side, causing a little slackness in the weft yarn. So, more will be the crimp in weft, hence resulting in decrease in the fabric width[14].

The combination of factor levels for obtaining maximum fabric width was found to be $A_{1} B_{2} C_{2} D_{1}$, corresponding to a $4200 \mathrm{~N}$ warp tension, medium temple needle, intense take-up pressing tension and $1900 \mathrm{~mm}$ loom working width.

The fabric width values predicted from the Taguchi design for combinations of input variables not used in the original Taguchi design of experiment are given in Table 8. 
Table 8: Comparison of experimental results with fabric width predicted from Taguchi design

\begin{tabular}{|c|c|c|c|c|c|c|c|}
\hline \multirow{2}{*}{ A } & \multirow{2}{*}{ B } & C & D & $\begin{array}{c}\text { Predicted fabric } \\
\text { width }(\mathbf{m m})\end{array}$ & \multicolumn{2}{|c|}{ Actual fabric width $(\mathbf{m m})$} & $\begin{array}{c}\text { Difference between } \\
\text { predicted and } \\
\text { actual width (mm) }\end{array}$ \\
\cline { 6 - 8 } & & & & Average & Standard deviation & -0.7 \\
\hline 1 & 1 & 1 & 2 & 1600.1 & 1600.8 & 1.3038 & 2.1 \\
\hline 1 & 2 & 1 & 1 & 1609.6 & 1604.2 & 1.1402 & 1.8 \\
\hline 1 & 2 & 2 & 2 & 1608.5 & 1607.6 & 0.8367 & 0.9 \\
\hline 2 & 1 & 1 & 1 & 1601.0 & 1599.8 & 1.2247 & 1.2 \\
\hline 2 & 1 & 2 & 2 & 1599.9 & 1602.2 & 1.0954 & -2.3 \\
\hline 2 & 2 & 1 & 2 & 1603.2 & 1603.8 & 1.3038 & -0.6 \\
\hline 2 & 2 & 2 & 1 & 1609.4 & 1609.2 & 1.3038 & 0.2 \\
\hline
\end{tabular}

Fabric samples were also manufactured on these combinations of input variables, followed by the measurement of their actual length. A comparison of the difference between the predicted and the actual width values in Table 8 shows good agreement between the predicted and actual values.

\section{Conclusion}

Weaving parameters could be optimised for obtained controlled off-loom fabric width using cost-effective Taguchi approach. It was concluded that the use of medium-sized temple needle and intense take-up pressing tension results in maximum fabric width at a relatively lower warp tension. Also, a smaller loom working width resulted in maximising the fabric width. The ANOVA test was used to determine the effect of independent variables on the dependent variable. Based on the ANOVA, it was further concluded that temple needle size was the most significant factor affecting the fabric width, followed by loom working width and warp tension, whereas take-up pressing tension was the least significant factor of all the factors investigated in the study.

\section{REFERENCES}

[1] Adanur, S. Handbook of Weaving, 1st ed. New York: CRC Press, 2002, p. 436.

[2] Kovar, R. "Length of the yarn in plain weave crimp wave," Journal of the Textile Institute, vol. 102, no. 7, pp. 582-597, Jul. 2011.

[3] Chahal, V. and Mohamed, M. H. "Measuring Filling Yarn Tension and Its Influence on Fabrics Woven on a Projectile Weaving Machine," Textile Research Journal, vol. 56, no. 5, pp. 324-333, May 1986.

[4] Syed, U., Jhatial, R. A. and Peerzada, M. H. "Influence of Warp Yarn Tension on Cotton Woven Fabric Structures," Mehran University Research Journal of Engineering \& Technology, vol. 32, no. 1, pp. 125-132, 2013.
[5] Kennamer, H. G. , Mayne, S. C. and Berkley, E. E. "The Effects of Fiber Fineness (Micronaire) on the Weaving Contraction in Selected Cotton Fabrics," Textile Research Journal, vol. 26, no. 10, pp. 812-820, Oct. 1956.

[6] Qadir, B., Hussain, T. and Malik, M. "Effect of Elastane Denier and Draft Ratio of Core-Spun Cotton Weft Yarns on the Mechanical Properties of Woven Fabrics," Journal of Engineered Fabrics \& Fibers, vol. 9, no. 1, pp. 23-31, 2014.

[7] Mahbubul, Haque Md. "Effect of Wect Parameters on Weaving Performance and fabric Properties," Daffodil International University Journal of Science and Technology, vol. 4, no. 2, pp. 62-69, 2009.

[8] Basu, A. K. "Effect of Different Let-off Mechanisms on Fabric Formation and Dimension of Fabric in the Loom," Textile Research Journal, vol. 57, no. 7, pp. 379-386, Jul. 1987.

[9] Adomaitienè, A. Ravinienè, G. and Kumpikaité, E., "Influence of Weaving Loom Setting Parameters on Changes of Woven Fabric Structure and Mechanical Properties," Materials Science, vol. 17, no. 4, pp. 417-422, 2011.

[10] Marks, R. Robinson, ATC. Principles of Weaving. Manchester: The Textile Institute, 1976.

[11] Sriramulu, A. T. Weaving Machines Mechanism Management, 2nd ed. Ahmedabad: Mahajan Publishers, 1998.

[12] Park, C. K. "A Process for Optimizing Sewing Conditions to Minimize Seam Pucker Using the Taguchi Method," Textile Research Journal, vol. 75, no. 3, pp. 245-252, Mar. 2005.

[13] ASTM D 3774 "Standard test method for the width of textile fabric" 1996.

[14] Zeydan, M. "Modelling the woven fabric strength using artificial neural network and Taguchi methodologies," International Journal of Clothing Science and Technology, vol. 20, no. 2, pp. 104-118, 2008.

[15] Behera, B. and Hari, P. Eds., Woven Textile Structure, 1st ed. Cambridge: Woodhead Publishing Limited, 2010. 